\title{
A Building Classification System for Multi-hazard Risk Assessment
}

\author{
Vitor Silva $^{1} \cdot$ Svetlana Brzev $^{2} \cdot$ Charles Scawthorn $^{3} \cdot$ Catalina Yepes $^{1} \cdot$ \\ Jamal Dabbeek $^{4} \cdot$ Helen Crowley $^{5}$
}

Accepted: 2 February 2022/Published online: 17 February 2022

(C) The Author(s) 2022

\begin{abstract}
A uniform and comprehensive classification system, often referred to as taxonomy, is fundamental for the characterization of building portfolios for natural hazard risk assessment. A building taxonomy characterizes assets according to attributes that can influence the likelihood of damage due to the effects of natural hazards. Within the scope of the Global Earthquake Model (GEM) initiative, a building taxonomy (GEM Building Taxonomy V2.0) was developed with the goal of classifying buildings according to their seismic vulnerability. This taxonomy contained 13 building attributes, including the main material of construction, lateral load-resisting system, date of construction and number of stories. Since its release in 2012, the taxonomy has been used by hundreds of experts working on exposure and risk modeling efforts. These applications allowed the identification of several limitations, which led to the improvement and expansion of this taxonomy into a new classification system compatible with multi-hazard risk assessment. This expanded taxonomy (named GED4ALL) includes more attributes and several details relevant for buildings exposed to natural hazards beyond earthquakes. GED4ALL has been applied in several international initiatives, enabling the identification of
\end{abstract}

Vitor Silva

vitor.silva@globalquakemodel.org

Risk Section, Global Earthquake Model, 27100 Pavia, Italy

2 Department of Civil Engineering, University of British Columbia, Vancouver, BC V6T 1Z4, Canada

3 SPA Risk LLC, Denver, CO 80207, USA

4 Department of Civil Engineering, An-Najah National University, Nablus, State of Palestine

5 Seismic Risk Section, 27100 Eucentre, Pavia, Italy the most common building classes in the world, and facilitating compatibility between exposure models and databases of vulnerability and damage databases.

Keywords Disaster risk - Exposure - Multihazard · Taxonomy

\section{Introduction}

Natural hazard risk assessment is critical for the development and implementation of disaster risk management measures. A risk assessment usually entails the characterization of the hazards affecting the region of interest (that is, expected frequency and intensity of the hazards), the definition of the vulnerability of the assets exposed to the hazards (that is, likelihood to suffer damage or loss), and a classification of the assets in the region. In large-scale risk analyses, it might be economically prohibitive to classify each exposed asset individually. Instead, the assets are grouped into categories based on a set of attributes relevant for characterizing their vulnerability to the hazards of interest. It is thus fundamental to ensure that the attributes and the associated details are sufficiently comprehensive, but at the same time flexible and able to account for the particularities of the built environment at any location in the world.

The recognition of the need to classify the building stock propelled the development of several building classification systems in the last few decades, including the ATC-13 (ATC 1985), the European Macroseismic Scale (EMS-98) (Grünthal 1998), HAZUS (FEMA 2003), PAGER-STR (Jaiswal and Wald 2008), and the Syner-G (Crowley et al. 2011) taxonomy. Despite the usefulness of these existing classification systems, and in some cases 
their pioneering character, a review of their strengths and limitations highlighted some important gaps that render them difficult to apply at a global scale. For example, the ATC-13 taxonomy is focused mostly on the type of construction found in California, while the HAZUS taxonomy addresses only construction practices common for the United States. Other taxonomies such as the EMS-98 include a limited number of building classes that exist mostly in Europe. Most of the existing taxonomies are limited to a fixed list of building classes, and therefore lack the required flexibility to characterize buildings and building classes at the locations of interest. For these reasons, the Global Earthquake Model (GEM) Foundation supported the development of a new global building taxonomy to characterize the building stock for seismic vulnerability and risk assessment purposes. The development of this global taxonomy (known as the GEM Building Taxonomy V2.0) was completed in 2012 (Brzev et al. 2013). The taxonomy was subsequently released to the scientific community for application in urban, national, and global exposure and vulnerability modeling efforts. The goal of these applications was to evaluate the taxonomy and identify its limitations and gaps. After an initial testing period the taxonomy was improved and further expanded to include attributes relevant to other natural hazards. This modification of the taxonomy was performed within the scope of the Global Facility for Disaster Reduction and Recovery (GFDRR) Challenge Funds initiative, supported by the (formerly known as) Department for International Development (DFID) of the United Kingdom.

This article presents an overview of the relevant building classification systems that were reviewed to identify the required characteristics of a global uniform building taxonomy (GEM Building Taxonomy V2.0), and then describes the testing of the taxonomy during the initial 5 -year period that allowed the identification of its limitations and the expansion of the taxonomy to multi-hazard risk modeling applications (GED4ALL Building Taxonomy, GED stands for Global Exposure Database). Four applications of the taxonomy are presented, describing the comparison of the building stock between different European countries and the estimation of losses due to earthquakes and floods in the Middle East. The attributes and associated options for this taxonomy are supported by an online glossary, ${ }^{1}$ and all of the information is available through a public repository on GitHub. ${ }^{2}$

\footnotetext{
${ }^{1}$ https://taxonomy.openquake.org/

${ }^{2}$ https://github.com/gem/gem_taxonomy
}

\section{A Review of Existing Building Taxonomies}

Several existing taxonomies were reviewed in the process of developing the GEM Building Taxonomy. The majority of these taxonomies are focused on structural aspects, and were developed to describe and classify building structures in terms of their seismic performance. A few relevant building taxonomies developed in the United States are mostly focused on local design and construction practices (for example, ATC-13, FEMA 154, and HAZUS). ATC-13 (ATC 1985) was a pioneering effort to develop a facility classification scheme for California, including engineering and social function classifications. The engineering classification contains 78 classes of structures, 40 of which are related to buildings and 38 are related to other structure types (for example, bridges, storage tanks, towers). Key engineering characteristics include construction material, structural framing system, configuration, design and construction quality, age, and height. FEMA 154 (FEMA 1988) classified buildings into 15 broad structural classes, including 5 classes for reinforced and precast concrete buildings, 3 classes for masonry buildings, 5 classes for steel buildings, and 2 classes for wood buildings. Most classes address only vertical structural system, while the type of diaphragm (rigid/flexible) was considered only for masonry buildings. HAZUS (FEMA 2003) is one of the most popular US-focused taxonomies, which contains 36 structural categories, some classified according to 3 height ranges (low-rise, mid-rise, and high-rise). Some materials and construction technologies were not included in HAZUS (for example, earthen and stone construction).

Several building taxonomies have been developed in Europe. For example, the EMS-98 scale (Grünthal 1998) is a widely used European taxonomy, which classifies buildings into 15 broad classes, including 7 masonry, 6 reinforced concrete (RC), steel, and timber buildings. Each building class has been assigned an expected seismic vulnerability rating, ranging from $\mathrm{A}$ (most vulnerable) to $\mathrm{F}$ (least vulnerable). The level of seismic design has been considered only in the context of RC structures (without design, moderate level of design, high level of design). In another effort, a building taxonomy comprising 23 classes grouped according to the structural type, material of construction, height class, and building design code level, was proposed for seven European cities under the RISK-UE project (Mouroux et al. 2004). More recently, the Syner-G taxonomy was developed for classifying European buildings (Crowley et al. 2011), and it is characterized by a strong flexibility due to the absence of a hierarchy, which is considered to be an advantage compared to other building taxonomies. It consists of 15 facets (lists of categories) and can be used to classify buildings and bridges. 
Only a few among the existing taxonomies have a global focus and applicability. The World Housing Encyclopedia (WHE) (EERI 2000) is a database of housing construction practices from more than 45 countries and regions, and it includes structural, architectural, and socioeconomic information. The focus is on seismic safety of housing, hence the vulnerability rating (based on the EMS-98 scale), damage observed in past earthquakes, as well as the applied seismic retrofitting techniques, are also included. The structural taxonomy developed for the WHE consists of 14 housing construction types and 45 subtypes. Gravity and lateral load-resisting systems (LLRSs) can be independently assigned to a building. There are 20 options for floors and roofs, and 18 for foundations. Some structural types without seismic-resisting features, such as RC frames, have been itemized, but others (for example, shear walls and braced frames) are not, so there is a certain lack of rigor. PAGER-STR is the most comprehensive global building taxonomy developed before 2010 (Jaiswal and Wald 2008). According to the PAGER-STR taxonomy, buildings are classified into 101 classes, based on the material of the lateral load-resisting system, type of lateral load-resisting system, and building height. The taxonomy captures most of the key structural aspects that affect seismic performance, but does not account for some important factors, such as the provision of ductile detailing and geometrical irregularities. Structural systems such as reinforced concrete and steel structures have been subdivided into three building heights ( $1-3$ stories, $4-7$ stories, and $8+$ stories).

Most of the existing building taxonomies are focused on engineered buildings, and do not address characteristics of non-engineered and vernacular buildings, which are generally constructed by homeowners or builders without technical training. Most of these buildings are used for residential purposes, and some studies indicate that they comprise more than $90 \%$ of the world's housing stock in developing countries (Vellinga et al. 2007). Although some of the aforementioned taxonomies (for example, WHE and PAGER-STR) can be used to classify non-engineered buildings, the only reported taxonomy that specifically classifies buildings into engineered and non-engineered types was developed by Coburn and Spence (2002). In this taxonomy, building types are listed from the most vulnerable through the least vulnerable. However, many vulnerability parameters (besides the main structural classification and building type) are mentioned by the authors, but not included in the classification.

Only a few taxonomies have been developed for the purpose of classifying earthquake damage. The Cambridge Earthquake Impact Database (CEQID) contains damage data from more than 70 studies covering more than 600 locations in 53 earthquakes, and has identified almost 300 building classes (Lee et al. 2011). The building class descriptions in the CEQID taxonomy include the following parameters: (1) main construction material (for example, adobe, brick, reinforced concrete); (2) structural system (for example, steel moment resisting frame, shear wall); secondary attribute details (for example, walls, floors, roofs); age or age reference (for example, pre-1941, post1976, pre-code, modern code); height (for example, 2 to 3 stories, 4 to 10 stories), and occupancy type (for example, residential).

In the United States, several classification systems developed for construction industry applications have also been proposed. MasterFormat ${ }^{\mathrm{TM}}$ was initially published in 1963, and provides a list of construction works. UNIFORMAT $^{\mathrm{TM}}$ (first published in 1998) provides a standard method for arranging construction information, organized around the physical parts of a facility called systems and assemblies. The OmniClass Construction Classification System (OmniClass 2006) provides a standardized basis for classifying information created and used by the North American architectural, engineering and construction industry. OmniClass draws from MasterFormat ${ }^{\mathrm{TM}}$ for work results, UNIFORMAT ${ }^{\mathrm{TM}}$ for elements, and Electronic Product Information Cooperation (EPIC) for products. It consists of 15 hierarchical tables, each representing a different facet of construction information. Entries from different tables can be combined to classify more complex assets.

The review of these classification systems was fundamental to identify the main strengths of each taxonomy, and most importantly, to ensure that the existing limitations and gaps are mitigated in the new system. This review also enabled the collection of hundreds of construction and architectural features, which had to be properly captured by the global taxonomy.

\section{The Global Earthquake Model (GEM) Building Taxonomy V2.0: Classification of Buildings for Seismic Risk Assessment}

A novel building classification system, hereafter termed as the GEM Building Taxonomy V2.0, was developed in the period 2010-2012. The objective was to develop a uniform building classification system for seismic risk assessment purposes (Brzev et al. 2013). The vision was to create a unique description of a building or a building class that provides information regarding the attributes that are relevant for their seismic performance, or to relate an asset to a vulnerability class. The development of the GEM taxonomy followed four main principles: 
(1) To be complete: It must include all engineering features relevant to the global seismic performance of a building structure;

(2) To be collapsible: Taxonomic groups can be combined, but the resulting combinations will still distinguish differences in seismic performance;

(3) To be international in scope: It should be appropriate for application anywhere in the world;

(4) To be user-friendly: It should be easy to use by those collecting the data, those arranging for its analysis, and the end users.

This v2.0 of the building taxonomy used the following 13 attributes to describe individual buildings and building classes:

(1) Direction - the orientation of the lateral load-resisting system in two principal horizontal directions of the building plan, which are perpendicular to one another.

(2) Material of the lateral load-resisting system-the material of the structural members that resist the lateral loads or deformations (for example, masonry, wood).

(3) Lateral load-resisting system (LLRS) - the structural system that provides resistance against lateral loads or deformations through vertical and horizontal structural components (for example, walls, moment-frames).

(4) Height-building height above ground expressed in terms of the number of stories (for example, 3 stories). This attribute also includes information on the number of basements (if present) and the ground slope.

(5) Date of construction or retrofit - the year when the building was constructed. If the building consists of parts or portions that vary in age, the earliest date is used. If the structure of the building was retrofitted in a manner that improves its seismic performance, the date of the retrofit should be used instead of the date of construction.

(6) Occupancy-the type of activity or use of the building. It is possible to describe a diverse range of occupancies (for example, residential occupancies include informal housing (slums), as well as highrise apartment buildings).

(7) Building position within a block-the position of a building within a block of buildings (for example, a "detached building" is not attached to any other building).

(8) Shape of the building plan-the geometric shape of the building in plan (for example, L-shape, rectangular shape).
(9) Structural irregularity - a feature of a building's structural arrangement, such as a story that is significantly higher than other stories, an irregular building shape, or change of structural system or material that produces a known vulnerability during an earthquake. In recognition of the fact that a building may have more than one irregularity, the user is able to identify both a primary and secondary irregularity.

(10) Exterior walls - material of exterior walls (building enclosure) (for example, masonry, glass).

(11) Roof - the roof shape, material of the roof covering, structural system supporting the roof covering, and roof-wall connection. For example, roof shape may be "pitched with gable ends," roof covering could be "tile," and roof system may be "wooden roof structure with light infill or covering."

(12) Floor-floor material, floor system type, and floorwall connection. For example, floor material may be "concrete," and the floor system may be "cast inplace beamless reinforced concrete slab."

(13) Foundation system-part of the construction where the base of the building meets the ground. The foundation transmits loads from the building to the underlying soil. For example, a shallow foundation supports walls and columns in a building for hard soil conditions, and a deep foundation needs to be provided for buildings located in soft soil areas.

Depending on the available information and desired level of detail, each attribute can be described by up to three levels of detail. Fig. 1 shows the attributes of the GEM Building Taxonomy V2.0 (shown in grey). The first level of detail is shown in blue, the second level is shown in purple, and the third level is shown in yellow. Some attributes have three levels of detail. For example, for the Structural Irregularity, Level 1 describes the type of irregularity (that is, Plan or Vertical), Level 2 describes the Primary Irregularity, and Level 3 defines the Secondary Irregularity. The taxonomy scheme is flexible and provides an opportunity for adding new attributes and/or modifying the existing options.

Some of the building characteristics, especially materials, may require several details to account for a diversity of materials and technologies available at the global scale. For example, the Material attribute covers several materials, including concrete, masonry, steel, and wood. Masonry is described by the Level 1 attribute Material Type, which includes Masonry, Unreinforced (MUR); Masonry, Reinforced (MR); Masonry, Confined (MCF); and Masonry with unknown reinforcement (M99). Then, the Level 2 attribute Material Technology covers 13 types of masonry units (for example, adobe, stone), as illustrated in Fig. 2. 

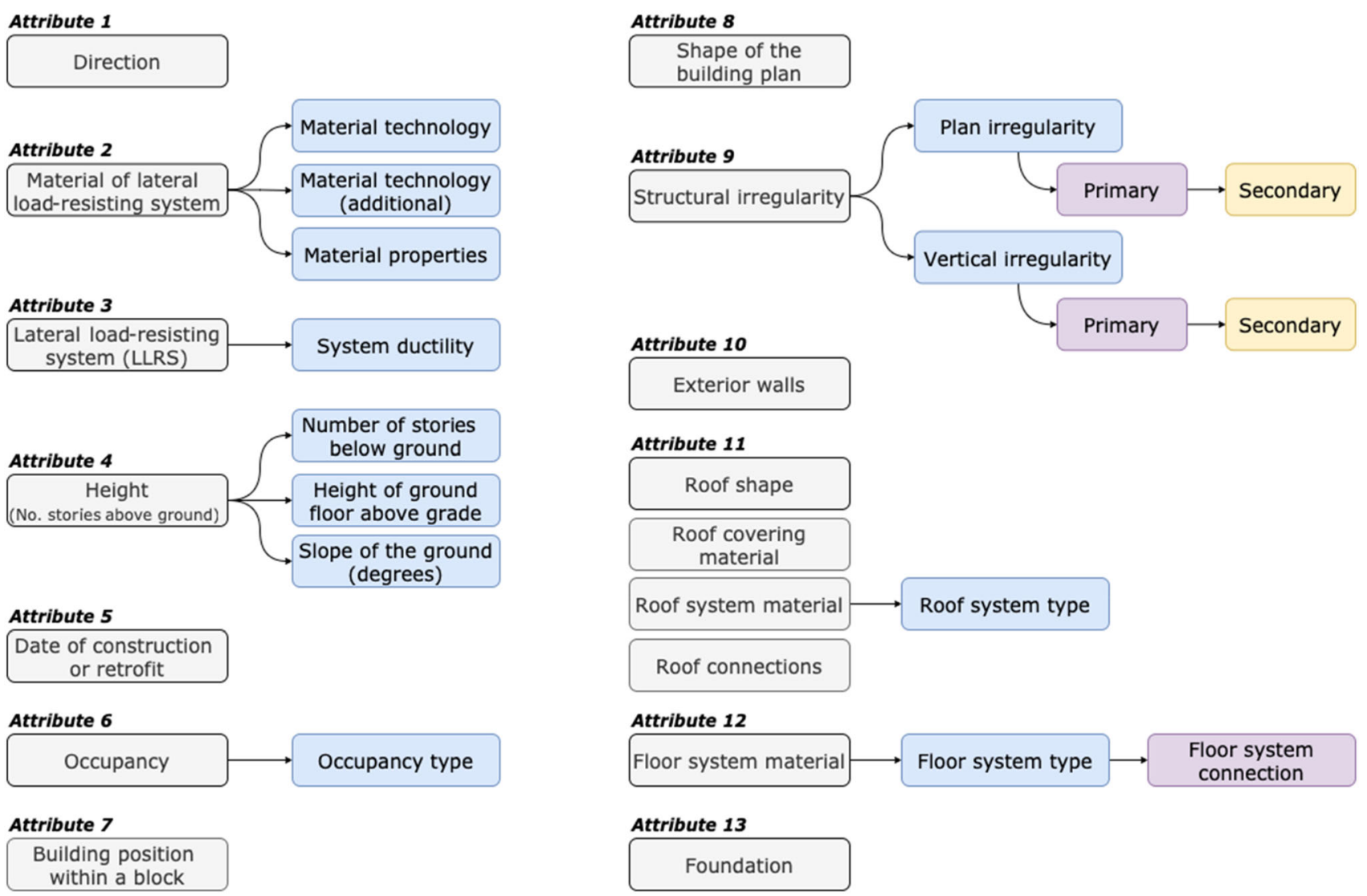

Fig. 1 Global Earthquake Model (GEM) Building Taxonomy V2.0: Attributes and levels of detail

According to the taxonomy, a building or a building class has a unique description in the form of an alphanumeric string, called "taxonomy string." This string can be interpreted as the "DNA" of the asset, as it is a combination of "codes" that contains the necessary information to classify the seismic performance. Table 1 presents three examples of widely different building typologies described using the GEM Building Taxonomy V2.0. The following key rules need to be followed to create the taxonomy strings:

- Each detail is described by a unique identifier (ID). For example, unreinforced masonry is defined by the identifier MUR (Masonry, Unreinforced).

- When information about an attribute or a specific level of detail is not available, a "99" entry can be assigned. For example, a building with unknown masonry technology is assigned the M99 identifier (Masonry, Unknown reinforcement).

- Attributes are entered in the same sequence as listed in the taxonomy schema (see Fig. 1), and need to be separated by the slash sign "/". Example 1 (Table 1) illustrates a taxonomy string that contains 13 attributes and details separated by slash signs.
- A plus sign (+) is used to include additional level of detail for a given attribute (for example, Level 1 or Level 2). Example 1 (Table 1) describes a cast-in-place reinforced concrete structure as $\mathrm{CR}+\mathrm{CIP}$, where $\mathrm{CR}$ denotes reinforced concrete and CIP denotes cast-inplace technology.

- In some cases, a numerical value is assigned. Example 3 (Table 1) presents a 14-story building, and the height is expressed in terms of the number of stories as HEX:14, where HEX denotes a height identifier, and 14 is the number of stories in the building.

A web-based tool, called TaxTweb, ${ }^{3}$ was developed as an online graphic interface for generating taxonomy strings through drop-down menus that contain text description of attributes and details. The GEM Foundation also maintains an online glossary, which was developed as a companion to the GEM Building Taxonomy V2.0 (Allen et al. 2013) and contains an illustrated description of each attribute and its details, ${ }^{4}$ as illustrated in Fig. 3.

The taxonomy includes several attributes that are directly correlated with the expected vulnerability of the assets

\footnotetext{
${ }^{3}$ https://platform.openquake.org/taxtweb/

${ }^{4}$ https://taxonomy.openquake.org/
} 


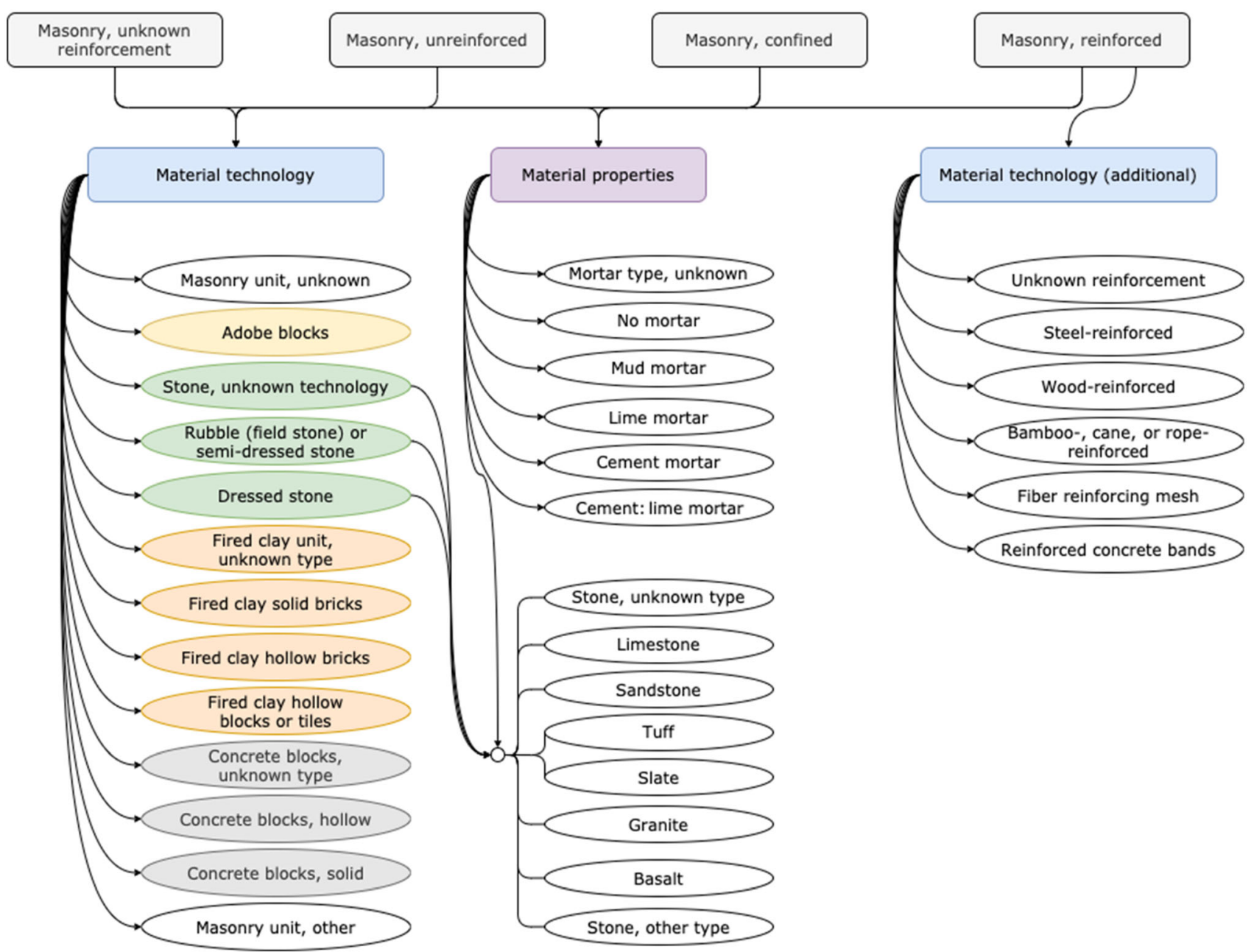

Fig. 2 Material attribute: Examples for Level 1 and Level 2 details for the Masonry attribute

regarding specific natural hazards. For example, the material of construction and the lateral load-resisting system are great indicators of the expected seismic vulnerability. The same is true for the type and material of the roof for cyclones or the presence of basements and height of the first story for floods. We note, however, that the taxonomy alone does not provide a quantification of the expected loss or damage given a hazard intensity. Instead, it allows users to either develop vulnerability models that account for these attributes (for example, Martins and Silva 2021), or to collect existing models from the literature compatible with the resulting taxonomy string (for example, Dabbeek et al. 2020).

\section{Testing and Application of the Global Earthquake Model (GEM) Building Taxonomy V2.0}

The GEM Building Taxonomy V2.0 was initially tested by the Earthquake Engineering Research Institute (EERI), through its World Housing Encyclopedia (WHE) project and its network of international members and colleagues (Gallagher et al. 2013). The purpose of the evaluation was to test the functionality and robustness of the taxonomy for global applications. The most important activity was to describe global building stock through the proposed taxonomy via online (TaxT) reports. In total, 217 TaxT reports from 49 different countries and six continents were collected as part of the evaluation process.

After this initial testing phase (which led to some minor adjustments), the classification system was applied to several projects. Some of these initiatives include the development of regional exposure models for South America (Yepes-Estrada et al. 2017), Central America and Europe (Crowley et al. 2012), national earthquake risk analyses (for example, Croatia (Kalman-Šipoš and Hadzima-Nyarko 2017), Iran (Motamed et al. 2019), and Costa Rica (Calderon and Silva 2019)), multi-hazard vulnerability assessments for schools (for example, Nassirpour et al. 2018; Adhikari et al. 2018), individual building exposure models for induced seismicity risk analysis (Crowley, Pinho, et al. 2019), and global dynamic exposure modeling 
Table 1 Illustrative examples of applications of the Global Earthquake Model (GEM) Building Taxonomy V2.0

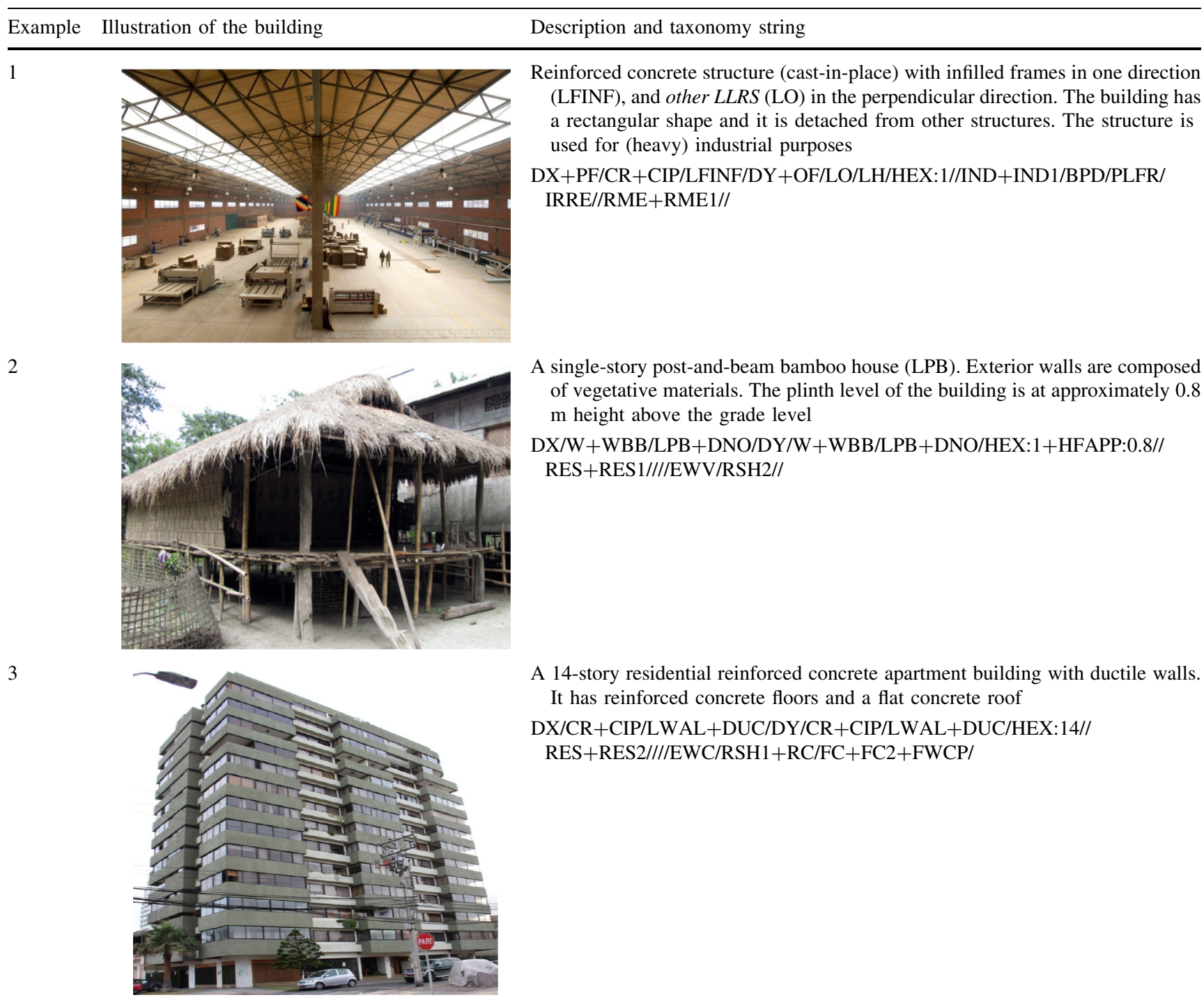

(for example, Pittore et al. 2017). The building taxonomy was also used for the characterization of the building stock as part of the initiatives supported by the World Bank (for example, Africa Disaster Risk Financing (ADRF) Initiative in 2017), and integrated in tools for building classification (Wieland et al. 2012) or management of fragility functions (Silva et al. 2014) as part of the projects supported by the European Commission. The use of the building taxonomy in these efforts with a variety of purposes allowed identifying some limitations and gaps, as described below:

(1) Insufficient detail in the seismic provisions: The original taxonomy only allowed classifying the ductility level of structures in ductile or non-ductile. Modern regulations can enforce different levels of ductility, which should be incorporated in the classification of each building class.

(2) Lack of flexibility in the definition of the main material of construction: It is common to find buildings that have more than one predominant material in the LLRS, especially in vernacular and informal construction. For example, some houses in the Caribbean are comprised of reinforced concrete moment resisting frames at the ground floor, and load-bearing masonry walls in the second floor.

(3) Lack of information regarding retrofitting interventions: The original taxonomy did not support any attribute to specify the presence of retrofitting interventions, which can obviously influence significantly the associated seismic vulnerability. 


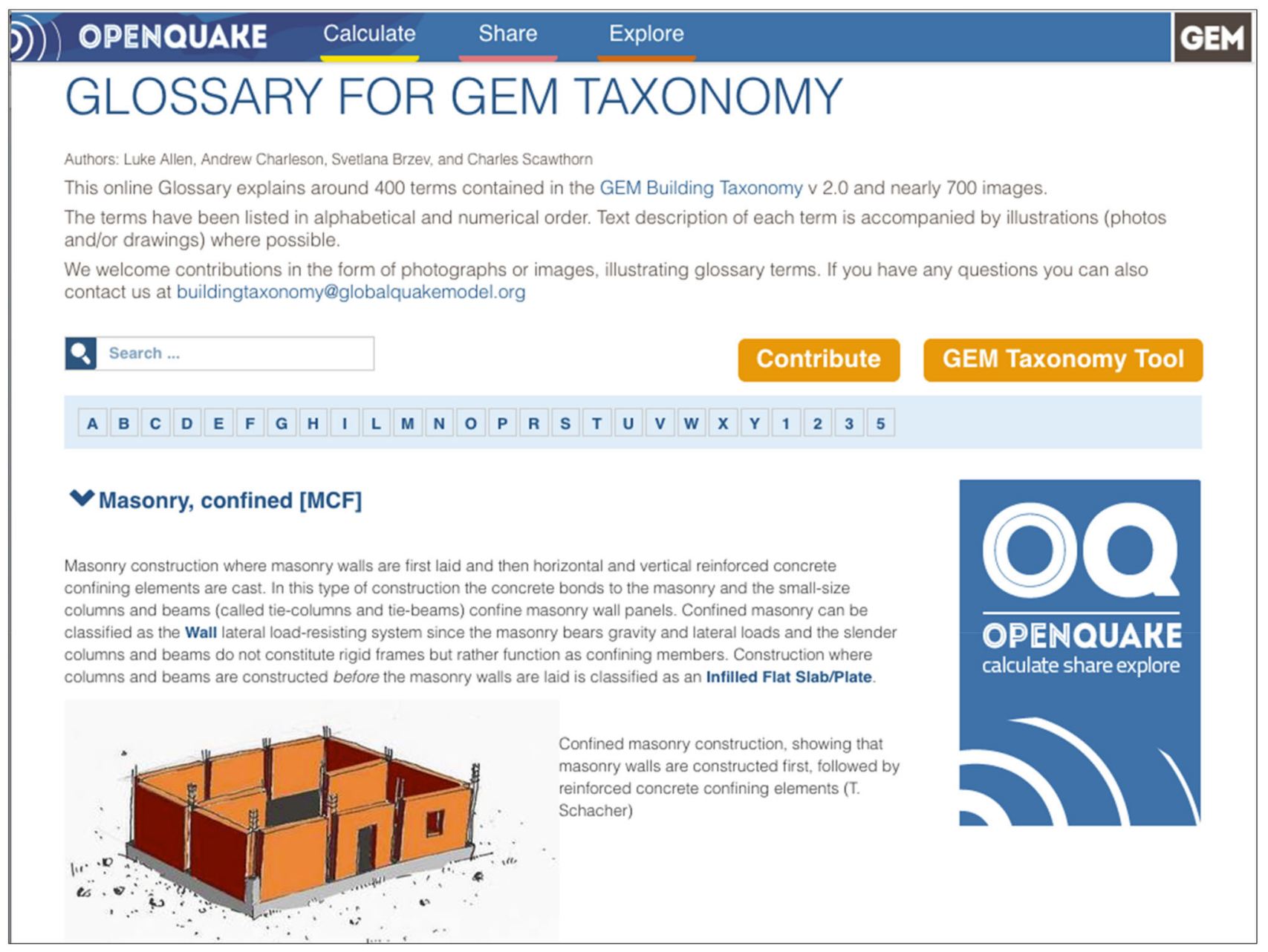

Fig. 3 Example of a glossary entry describing confined masonry (MCF) detail (Material of Lateral Load-Resisting System attribute) (https:// taxonomy.openquake.org/)

(4) Lack of information regarding the column/wall density: The density/ratio of the columns and walls area with respect to the building plan area, which was not included in the initial taxonomy, can be an indicator of the expected seismic vulnerability of the building.

(5) Disregard of attributes relevant to other hazards: One of the most commonly indicated limitations was the fact that other hazards besides earthquakes were not properly considered in the development of the classification system. Given that exposure modeling is often performed for multi-hazard purposes, the lack of specific attributes or options for other perils excluded the use of this taxonomy in some occasions.

(6) Complex taxonomy strings: One of the main goals of the initial taxonomy was to be as comprehensive and flexible as possible. However, as a consequence, the resulting taxonomy string became relatively complex, and difficult to use by users without an engineering background or training.

A number of other minor limitations were also indicated by the users, mainly related with the lack of flexibility of some of the attributes (for example, height/number of stories, position of the building within a block, shape of the buildings), as well as the need to include additional material types for the roof and floor attributes.

\section{A Multi-Hazard Building Classification System (GED4ALL)}

The extension of the GEM Building Taxonomy V2.0 for multi-hazard applications was developed within the scope of the Global Challenges initiative led by the Global Facility for Disaster Reduction and Recovery (GFDRR) for the World Bank, supported by the (formerly known as) 


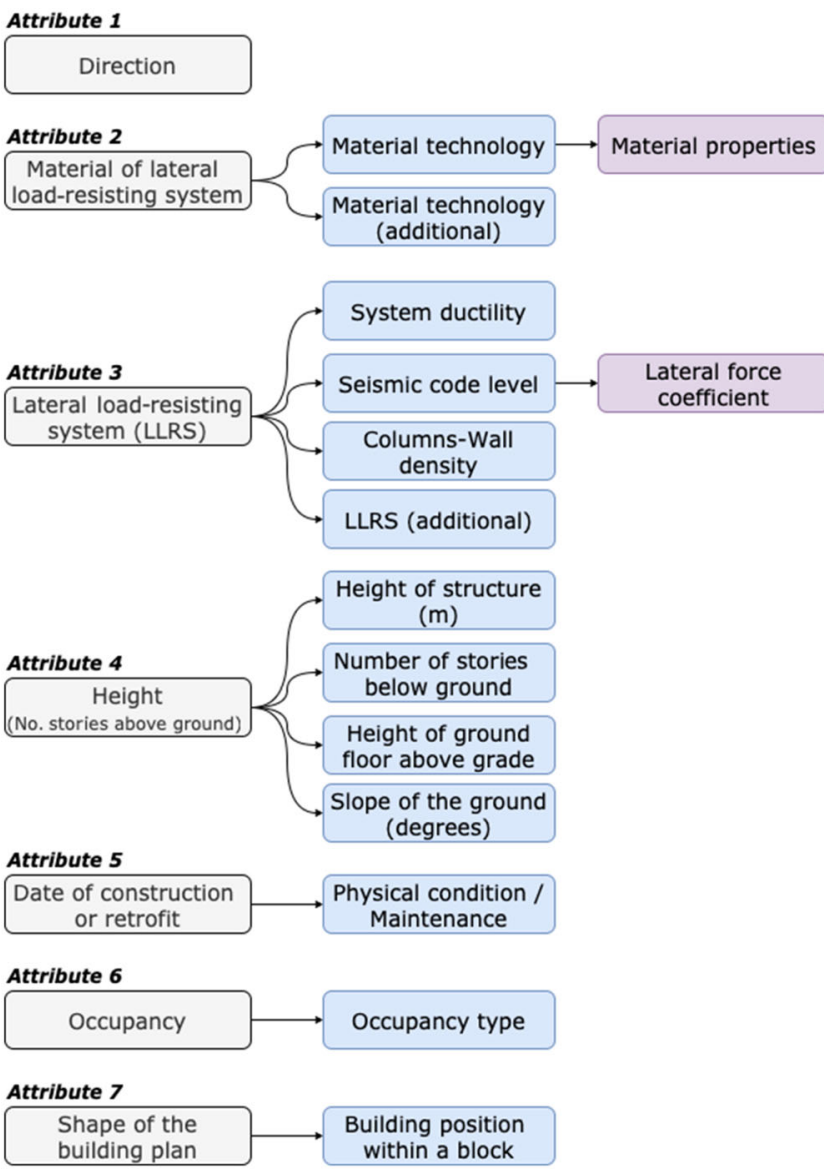

Fig. 4 GED4ALL Building Taxonomy attributes and levels of detail

Department for International Development (DFID) of the United Kingdom (Silva et al. 2018). In addition to the collected feedback and the expertise of the consortium, additional information was gathered at a workshop in London, UK in July 2017 with the participation of over 40 experts from the insurance and catastrophe modeling industry. The GEM Building Taxonomy V2.0 already contained several features fundamental for other hazards, (for example, information on the presence of basements, which is relevant for floods or type of roof, which is relevant for storms), but it was necessary to include a few attributes to address other hazards. The expanded taxonomy was named GED4ALL Building Taxonomy (GEDGlobal Exposure Database).

The GED4ALL Building Taxonomy has 14 attributes and enables users to describe a building or a building class by specifying attributes relevant to its structural response under multi-hazard actions. The general structure of this taxonomy is depicted in Fig. 4. The main attributes are shown in grey, Level 1 details are shown in blue, Level 2 details are shown in purple, and Level 3 details are shown in yellow. The following modifications were incorporated

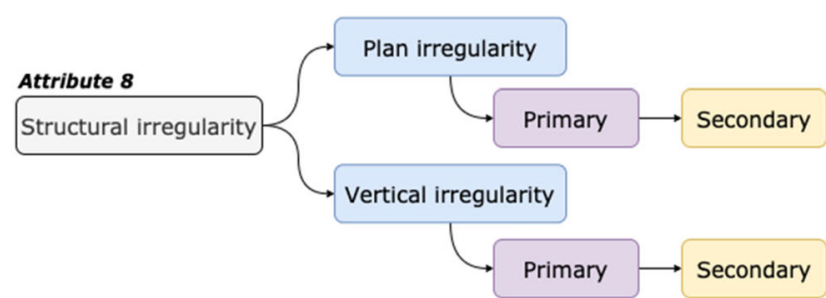

Attribute 9

Ground floor

hydrodynamics
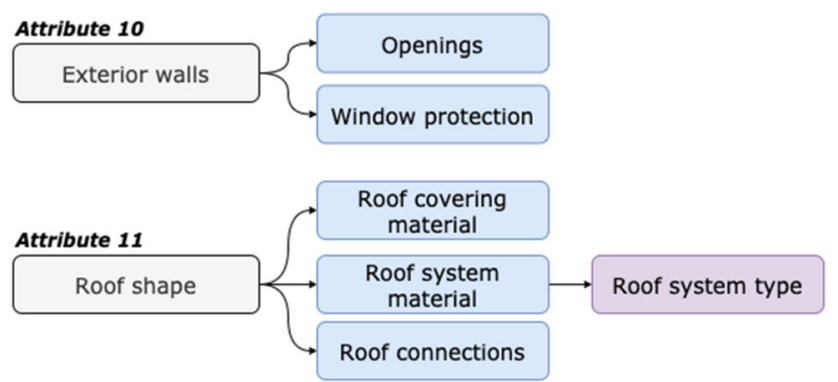

Attribute 12

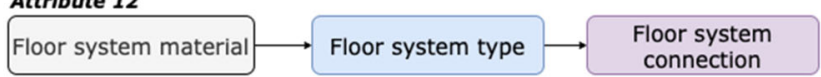

Attribute 13

Foundation

Attribute 14

Fire protection

in the GED4ALL taxonomy to account for multiple hazards:

- Attributes 7 and 8 from the initial version were grouped into one attribute, and two new attributes were added: (1) Attribute 9: ground floor hydrodynamics (relevant to flood hazard) and (2) Attribute 14: fire protection (relevant to fire hazard).

- Addition of new levels of detail associated with the existing attributes (for example, openings in exterior walls related to the strong wind hazard).

In addition, a few relevant structural features have been added related to informal construction built using mixed materials and hybrid LLRSs. Moreover, new details were included within the LLRS attribute, related to the ductility characteristics and level of seismic code provisions. For the latter parameter, now it is also possible to specify the lateral force coefficient (LLC), which is a common parameter used by the vast majority of the seismic regulations to define the seismic demand (for example, Crowley, Despotaki, et al. 2021).

The following rules must be followed while describing buildings using the GED4ALL Building Taxonomy (only 
the rules different from the GEM Building Taxonomy V2.0 are presented):

- If the LLRS is the same in both directions, the "Direction" attribute can be omitted.

- The separator "/" only needs to be included between existing IDs, and can be omitted if consecutive IDs are not defined. For example, a reinforced concrete building with external masonry walls instead will be simply classified as CR/EWMA, instead of DX/CR//DY/ CR//I////EWMA///

- When specifying a range of values, the symbol "“-" will be used, instead of ",".

The taxonomy strings for the examples presented in Table 1, which illustrate the application of the GEM Building Taxonomy V2.0, are shown in Table 2 using the GED4ALL Building Taxonomy. It is possible to observe largely similar content of the taxonomy strings for the two taxonomies, as well as a simplification in the taxonomy strings for the GED4ALL taxonomy (see Examples 1 and 2). Example 3 illustrates the manner in which information regarding the LLRS in each direction is presented.

The proposed taxonomy does not replace common data management tools such as QGIS or ArcGIS. Instead, it allows users to classify building portfolios following a uniform classification system, which can then be imported into such tools for visualization and management purposes. In fact, the applications presented in the following section used both the proposed taxonomy and QGIS to classify and visualize the results.

\section{Applications of the GED4ALL Building Taxonomy}

The GED4ALL taxonomy has now been applied to several projects and linked to tools and databases relevant to earthquake engineering. This section presents how this global taxonomy can be used to compare the building stock across Europe, identify building classes contributing to earthquake losses in the Middle East, and support users in the selection of suitable vulnerability functions.

\subsection{Classifying the European Building Stock for Exposure Modeling}

The GED4ALL Building Taxonomy has been used to classify buildings in Europe for the exposure component of a new European seismic risk model developed under the SERA (Seismology and Earthquake Engineering Research Infrastructure Alliance for Europe) project (Crowley, Rodrigues, et al. 2019; Crowley et al. 2020a). The European exposure model has been developed using many sources of public information, with a significant contribution coming from national population and housing censuses (Crowley et al. 2020b, c). The properties used to describe the dwellings and buildings in these censuses vary significantly across Europe and it was thus necessary to develop mapping schemes to infer the most probable building classes from the available properties. It was important to standardize the attributes of the building classes used in these mapping schemes, and the following subset of attributes of the GED4ALL Building Taxonomy was selected to classify buildings in the European countries: (1) Material of LLRS; (2) LLRS, including details such as seismic code level and lateral force coefficient; and (3) height (see Fig. 4). In some countries where more detailed building data were available, additional attributes related to structural irregularity and floor system material were also used in the mapping schemes.

The lateral force coefficient has only been computed for reinforced concrete buildings and has been estimated using the date of construction and location of the buildings. A study on the spatial and temporal evolution of seismic codes across Europe (Crowley, Despotaki, et al. 2021) has allowed the seismic code level to be assigned based on the date of construction. The following four levels of seismic design have been identified: (1) CDN: pre-code, no seismic design; (2) CDL: low code; (3) CDM: moderate code; and (4) CDH: high code. Furthermore, in Crowley, Despotaki, et al. (2021), seismic zonation maps associated with the

Table 2 A comparison of taxonomy strings for the Global Earthquake Model (GEM) V2.0 and GED4ALL building taxonomies

\begin{tabular}{lll}
\hline Example & GEM building taxonomy V2.0 & GED4ALL building taxonomy \\
\hline 1 & DX/CR+CIP/LWAL+DUC/DY/CR+CIP/LWAL+DUC/HEX:14// & CR+CIP/LWAL+DUH/H:14/RES2/EWC/RSH1+RC/ \\
& RES+RES2////EWC/RSH1+RC/FC+FC2+FWCP/ & FC+FC2+FWCP \\
2 & DX/W+WBB/LPB+DNO/DY/W+WBB/LPB+DNO/ & W+WBB/LPB+DNO/H:1+HFAPP:0.8/RES1/EWV/RSH2 \\
& HEX:1+HFAPP:0.8//RES+RES1///EWV/RSH2// & \\
3 & DX+PF/CR+CIP/LFINF/DY+OF/CR+CIP/LH/HEX:1// & DXP/CR+CIP/LFINF+MCR/DYO/CR+CIP/LHP(LFINF- \\
& IND+IND1/BPD/PLFR/IRRE//RME+RME1// & LPB)/H:1/IND1/PLFR+BPD/IRE/RSH2+RME1 \\
\hline
\end{tabular}


seismic design codes employed in Europe over the last century have been geocoded to estimate the lateral force coefficient (that is, the fraction of weight specified as the design lateral force, in \%) from the code level and building location. The inclusion of the code level and lateral force coefficient in the taxonomy has resulted in improved mapping between the exposure and vulnerability in the European risk model, as the vulnerability models of reinforced concrete buildings have been developed through simulated design of prototype buildings to different design codes and lateral force levels (Romão et al. 2019).

The use of a uniform taxonomy to classify the buildings in the exposure model across Europe has allowed the key characteristics of the buildings to be easily summarized and compared. For example, it is now possible to easily extract the total number of buildings in Europe constructed using different materials and LLRSs, with different number of stories, or designed to each level of seismic design codes (Fig. 5). This information can also be compared between countries, as shown in Fig. 6, which presents the proportion of reinforced concrete buildings designed to different code levels in each European country.

\subsection{Classifying the Residential Building Stock in the Middle East for Loss Assessment}

Dabbeek and Silva (2019) developed an exposure model for the residential building stock in 12 countries in the Middle East, for the purpose of estimating economic losses due to earthquakes and floods in the region (Dabbeek et al. 2020). This region is characterized by a heterogeneous built environment due to historical construction practices, which include historic adobe constructions in towns like Shibam in Yemen, and high-rise modern construction in countries with a strong economic development (for example, Qatar and United Arab Emirates). The authors reviewed previous studies focused on the characterization of the building stock for selected towns in the region, based on either customized classification systems or adapted existing taxonomies (Erdik et al. 2012; Grigoratos et al. 2016). The majority of these existing studies focused on the assessment of vulnerability and risk due to earthquakes, thus disregarding any relevant requirements pertaining to the assessment of the impact due to other hazards. These issues prevented the direct comparison of the exposure datasets between the various countries or cities and their application to multi-hazard risk assessment.

Dabbeek and Silva (2019) collected data regarding the most recent housing census for each country in the region, and established a relation between the variables used in the housing census (for example, material of the walls, number of stories, and housing type) and the attributes and details contained in the GED4ALL Building Taxonomy. Due to the lack of detailed data and the need to perform a regional risk analysis, the authors focused mostly on the attributes relevant to earthquakes (that is, material of the LLRS, LLRS, height, and level of ductility) and floods (that is, presence of basements and height of the first story in relation to the ground). The results indicated an estimated 14.8 million buildings and 21.7 million dwellings. The study showed that reinforced concrete is the predominant construction material in the region, and that reinforced concrete buildings account for about $53 \%$ of the housing stock; out of these, $46 \%$ are infilled frames and the remaining $7 \%$ are dual frame-wall systems. The second most common material is masonry, accounting for $36 \%$ of the housing stock and comprising mostly of unreinforced masonry buildings and a small fraction of confined masonry buildings.

The exposure model classified according to the GED4ALL Building Taxonomy was combined with earthquake and flood hazard models and a set of vulnerability functions to estimate risk metrics useful for disaster risk management. The disaggregation of the resulting risk according to the attributes of the taxonomy identified the construction types contributing the most to the regional and national risks. Fig. 7 presents the disaggregation of the seismic risk in terms of the main construction material (adobe, concrete, and masonry) and height (low, mid, and high rise) for each country in the region. In this example the seismic risk is expressed in terms of the average annual losses, as discussed in Dabbeek et al. (2020). ${ }^{5}$

\subsection{Linking Exposure Models with Data Capture Tools, Damage Data, and Vulnerability Functions}

In addition to allowing a direct comparison of characteristics of the built environment between different regions, or the disaggregation of losses according to the main structural attributes, a building classification system can enable users to link their exposure model with resources useful for data collection, risk assessment, and verification/calibration of models.

The GEM Building Taxonomy V2.0 was originally implemented in the Inventory Data Capture Tool (IDCT ${ }^{6}$, see Fig. 8), an Android application for mobile devices that allows users to collect building-by-building information in the field. This tool was used in Cali (Colombia) to collect

\footnotetext{
5 The exposure models developed in this study are available in the following public repository: https://github.com/jamaldabbeek/Expo sure-data.

${ }^{6}$ https://play.google.com/store/apps/details?id=org.globalquakemo del.org.idctdo
} 

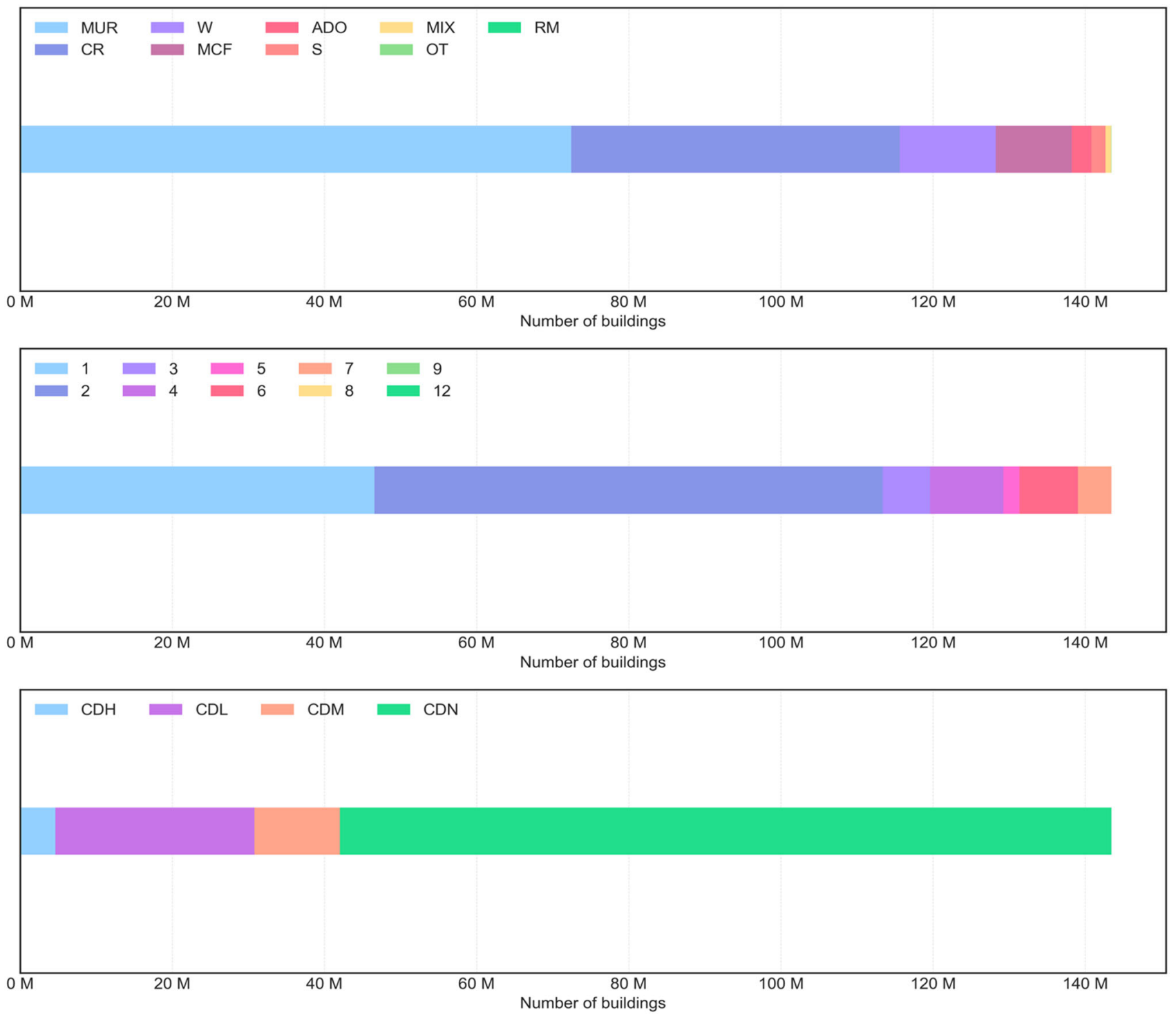

Fig. 5 Distribution of European buildings (million) in terms of the material type (top), height (middle), and code level (bottom). MUR Masonry, unreinforced; $C R$ Reinforced concrete; $W$ Wood; $M C F$

information from more than 30,000 buildings (CI Ambiental 2019).

The same classification system was also implemented in the Remote Rapid Visual Screening tool (Wieland et al. 2012) developed by the German Research Centre for Geosciences (GFZ), which allows users to combine omnidirectional and remote sensing imagery to classify the building stock. More recently, a module was developed within the scope of the Global Challenges initiative supported by GFDRR, which allows converting data from OpenStreetMap (OSM) into the simplified GED4ALL Building Taxonomy, thus allowing users to take advantage of the millions of assets that have been catalogued within OSM. The application of the same building taxonomy
Masonry, confined, $A D O$ Adobe, $S$ Steel, $O T$ Other, $R M$ Reinforced masonry, $C D N$ no seismic design, $C D L$ low code, $C D M$ moderate code, $C D H$ high code

across different tools allows exchanging data across projects, as well as an unambiguous understanding of the structural features of the collected data, even in cases where the final users were not involved in the data collection process.

In the vast majority of cases, the exposure data are collected for the purpose of assessing the potential impact that natural hazards might have on the building stock. To this end, it is necessary to identify fragility or vulnerability functions (that is, model establishing the probability of damage or loss conditional on the hazard intensity) compatible with the building classes present in the exposure model. To facilitate this process, the GED4ALL Building Taxonomy has been endorsed in a number of vulnerability 


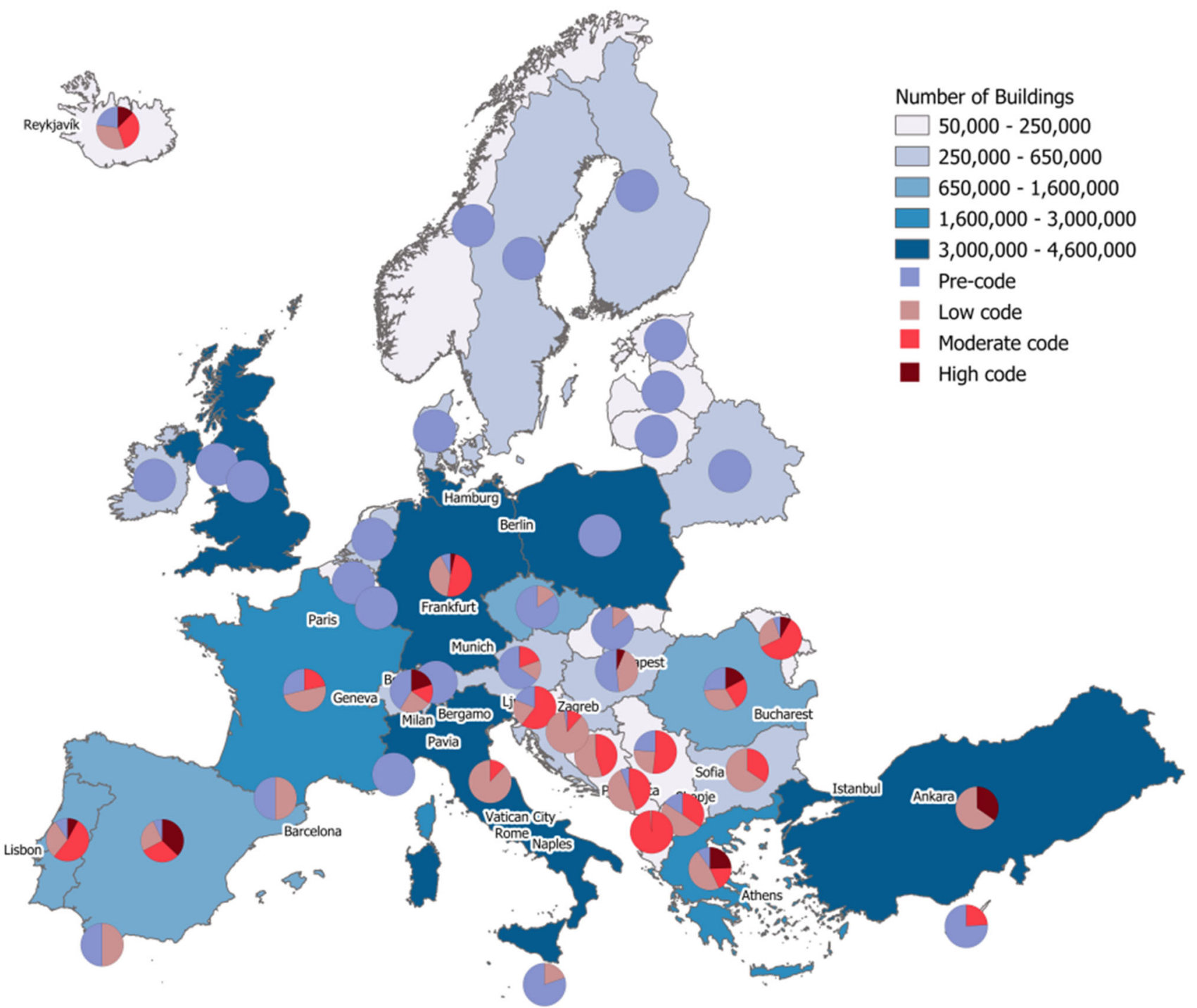

Fig. 6 The number of reinforced concrete buildings in each country in the European exposure model with pie-charts showing the fractions of pre-code (CDN), low code (CDL), moderate code (CDM), and high

assessment efforts. This classification system was embedded in the Vulnerability Database ${ }^{7}$ of the GEM Foundation, thus allowing modelers to search for suitable vulnerability functions based on key attributes (for example, main material of construction and LLRS). Moreover, vulnerability and fragility functions have been catalogued following the GED4ALL Building Taxonomy, allowing a better understanding of the structural features of the building (or building class) being represented by the respective model. Other initiatives related to the derivation of vulnerability functions that used this taxonomy include the Global Vulnerability Database (Martins and Silva 2021) supported by the United States Agency for

\footnotetext{
${ }^{7}$ https://platform.openquake.org/vulnerability/list
}

code $(\mathrm{CDH})$ buildings. Source Adapted from Crowley, Despotaki, et al. (2021)

International Development (USAID), as well as the vulnerability functions for the European reinforced concrete building stock supported by the European Commission as part of the H2020 European SERA project (Romão et al., 2020; Crowley, Silva, et al. 2021).

Finally, it is worth discussing the role of a building taxonomy in damage data collection and verification of vulnerability models. A building classification that is used to collect data in post-earthquake field missions is fundamental for understanding the fragilities of each building class, as well as for merging data collected by different surveyors or different missions. Moreover, the use of the same taxonomy between vulnerability modeling studies and damage collection missions allows the users to perform verification or calibration analyses, derivation of empirical 

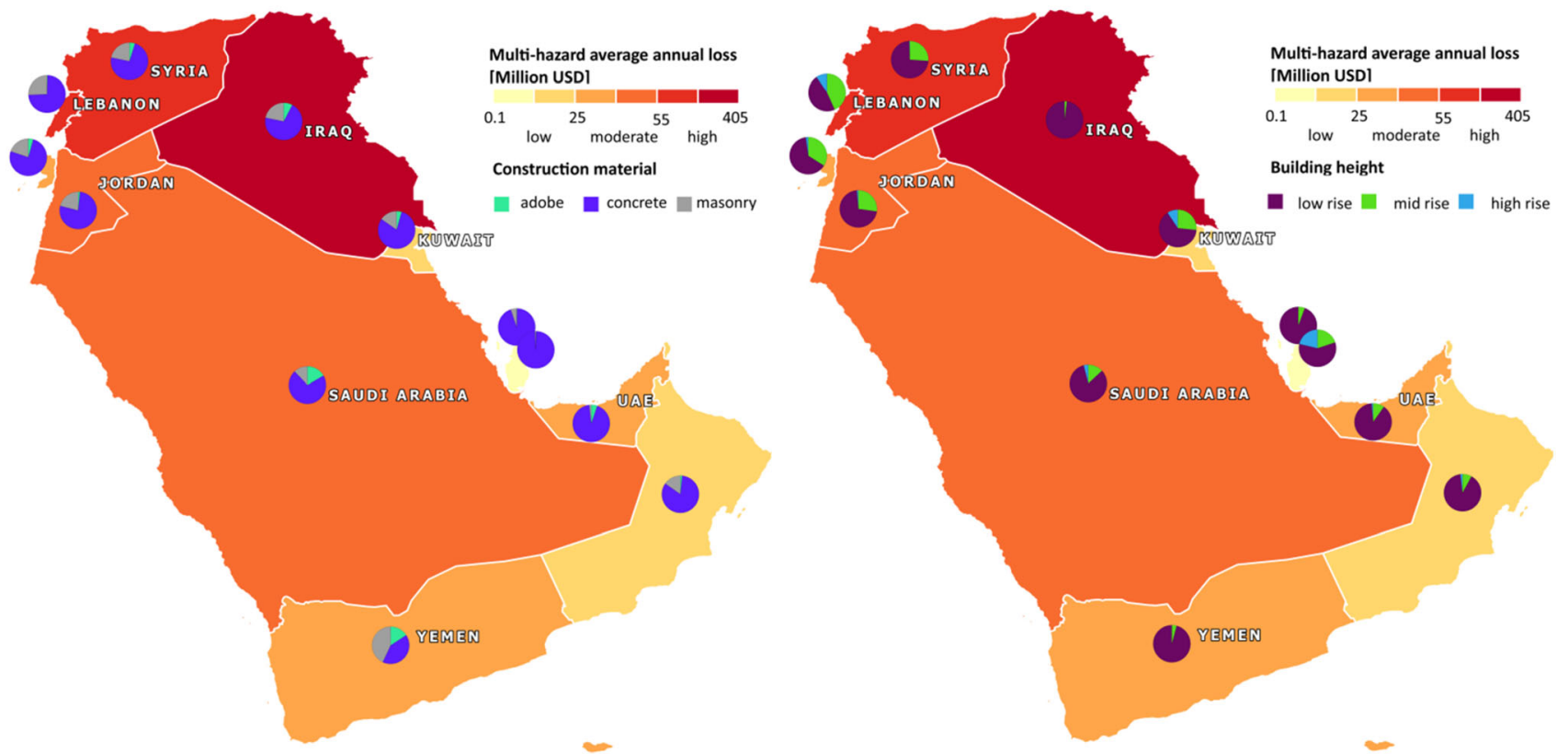

Fig. 7 Distribution of average annualized losses due to earthquakes and floods in the Middle East, disaggregated by main material of construction (left) and height (right) following the GED4ALL taxonomy
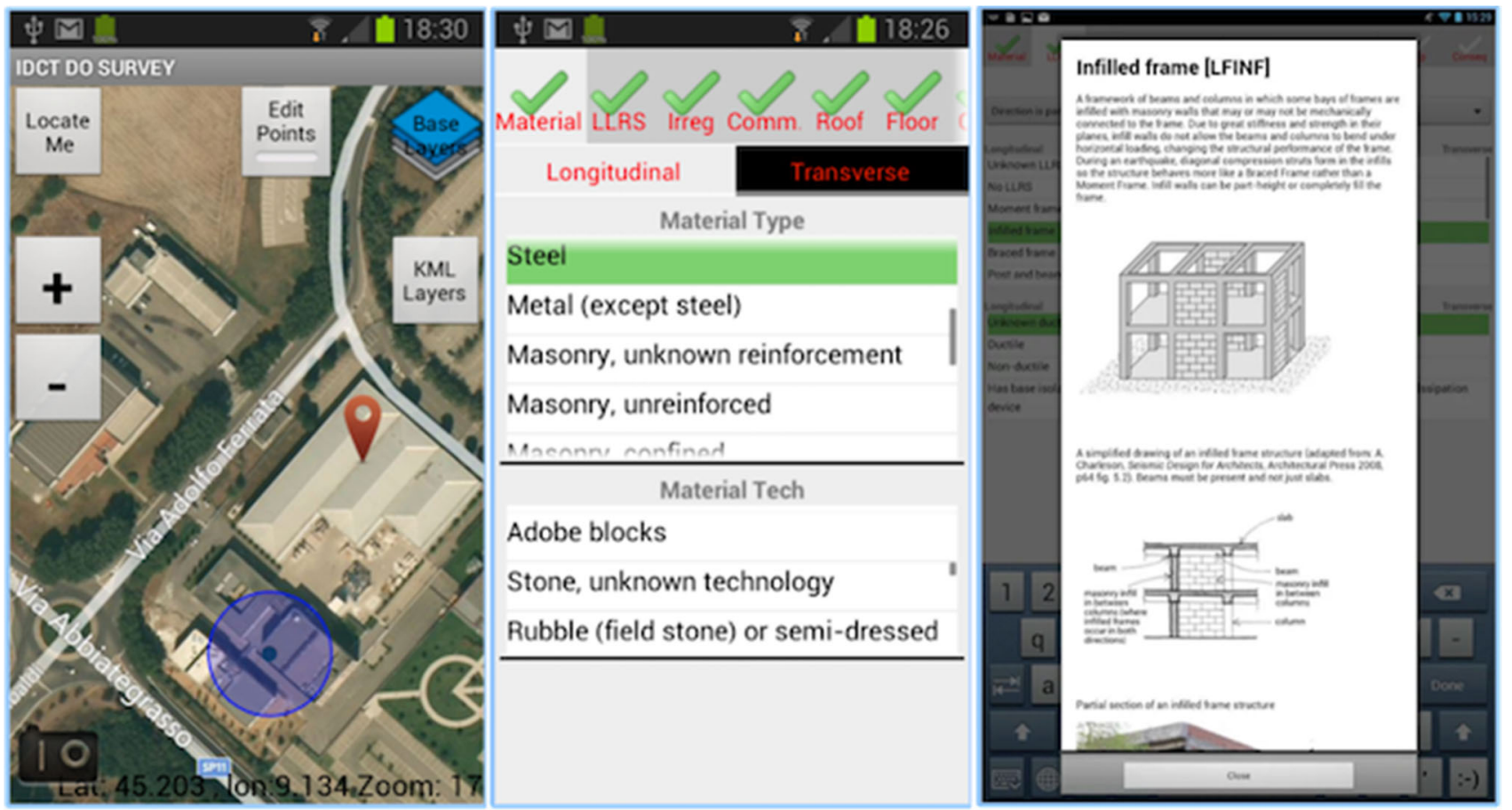

Fig. 8 Inventory Data Capture Tool using the Global Earthquake Model (GEM) Building Taxonomy V2.0

vulnerability functions (Rossetto et al. 2014), or the assessment of earthquake scenarios considering the characteristics of past events (Villar-Vega and Silva 2017). The Earthquake Consequences Database ${ }^{8}$ supported by the

\footnotetext{
8 https://platform.openquake.org/
}

GEM Foundation classified each asset according to the attributes defined by this taxonomy. Without a common language among these datasets and activities, it becomes either impossible to link data and models, or it requires a conversion process that might introduce unnecessary bias and uncertainty in the results. 


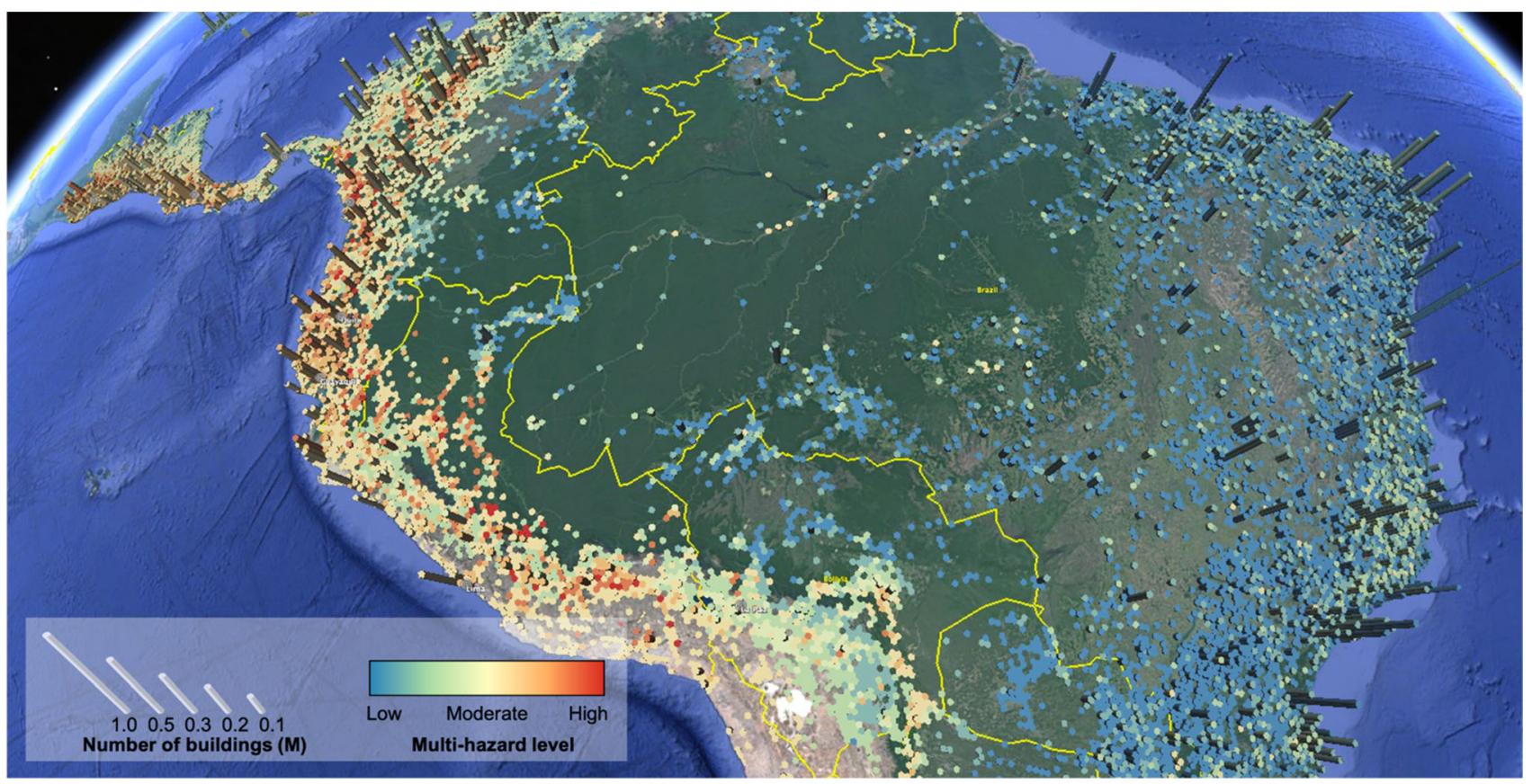

Fig. 9 Multi-hazard Exposure Index for Latin America, developed as part of the Global Resilience Index Initiative (GRII)

\subsection{Development of a Global Resilience Index}

A global effort was recently launched by a consortium of public and private partners that aims at providing a globally consistent model for the assessment of multi-hazard resilience across all sectors and regions. ${ }^{9}$ This effort will offer high level metrics across the built environment, infrastructure, agriculture, and population, with potential applications at different scales. In order to demonstrate the potential of this initiative, the residential, commercial, and industrial building stock for Latin America (which has been classified according to the taxonomy presented herein) is currently being used to create an indicator of exposure to multi-hazards in the region. Fig. 9 presents the preliminary results, in which the height of the polygons indicate the number of buildings and the color represents the level of exposure to multiple hazards.

\section{Conclusion}

This article presented a 10-year process to develop a comprehensive, modular, and flexible classification system to characterize single buildings or building classes for multi-hazard risk assessments. The initial version of the GEM Building Taxonomy (V2.0) focused on the classification of buildings for the purpose of seismic vulnerability assessment, and was tested through several national and regional seismic risk assessment initiatives. The initial testing and application of this taxonomy highlighted some important limitations, such as the inability to characterize assets for multi-hazard risk assessment, insufficient detail in the characterization of the seismic provisions, and lack of readability of the resulting taxonomy string. In fact, although most of the experts involved in the development of the taxonomy valued more the consideration of all possible architectural, structural, and material features, the majority of the users demonstrated a stronger preference for a simpler and easier-to-read classification system. These improvements were included in the GED4ALL Building Taxonomy, which is now a well-established classification system, incorporated in several national and international initiatives, as well as tools and databases. Some of the advantages of adopting a uniform building taxonomy were demonstrated using the European exposure model (Crowley et al. 2020b) and the multi-hazard risk assessment for the Middle East (Dabbeek and Silva 2019). More recently, this taxonomy has also been used for the development of a global seismic risk map (Silva et al. 2020).

All components of the GED4ALL Building Taxonomy are publicly available through a repository on GitHub. ${ }^{10}$ Previous versions of the taxonomy have also been included, given that some models developed in the past have followed older versions (for example, GEM Building Taxonomy V2.0). Moreover, future improvements and

\footnotetext{
${ }^{9}$ https://www.cgfi.ac.uk/global-resilience-index-initiative/
}

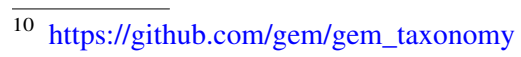


extensions of the GED4ALL taxonomy (in the repository referred as V3.0) will be included and documented in this public repository, thus allowing users to have permanent access to the latest (and most complete) version of the classification system.

Open Access This article is licensed under a Creative Commons Attribution 4.0 International License, which permits use, sharing, adaptation, distribution and reproduction in any medium or format, as long as you give appropriate credit to the original author(s) and the source, provide a link to the Creative Commons licence, and indicate if changes were made. The images or other third party material in this article are included in the article's Creative Commons licence, unless indicated otherwise in a credit line to the material. If material is not included in the article's Creative Commons licence and your intended use is not permitted by statutory regulation or exceeds the permitted use, you will need to obtain permission directly from the copyright holder. To view a copy of this licence, visit http://creativecommons. org/licenses/by/4.0/.

\section{References}

Adhikari, R., D. D'ayala, C. Ferreira, and F. Ramirez. 2018. Structural classification system for load bearing masonry school buildings. In Proceedings of the 16th European Conference on Earthquake Engineering, 18-21 June 2018, Thessaloniki, Greece.

Allen, L., A.W. Charleson, S. Brzev, and C. Scawthorn. 2013. Glossary for the GEM building taxonomy - GEM Technical Report 2013-03 V1.0.0. Pavia, Italy: GEM Foundation.

ATC (Applied Technology Council). 1985. Earthquake damage evaluation data for California, ATC-13. Redwood City, CA: Applied Technology Council.

Brzev, S., C. Scawthorn, A.W. Charleson, L. Allen, M. Greene, K. Jaiswal, and V. Silva. 2013. GEM building taxonomy version 2.0. GEM Technical Report 2013-02 V1.0.0. Pavia, Italy: GEM Foundation.

Calderon, A., and V. Silva. 2019. Probabilistic seismic vulnerability and loss assessment of the residential building stock in Costa Rica. Bulletin of Earthquake Engineering 17: 1257-1284.

CI Ambiental. 2019. Technical Report: Second stage of the evaluation of the vulnerability due to earthquakes in the urban area of the municipality of Santiago de Sali, for buildings of normal occupation - Use group I of the NSR-10 regulation V2 (Segunda etapa de la evaluación de la vulnerabilidad por sismos en la zona urbana del municipio de Santiago de Sali, para las edificaciones de ocupación normal - grupo de uso I del reglamento NSR-10 V2). Alcaldía de Santiago de Cali (in Spanish)

Coburn, A.W., and R. Spence. 2002. Earthquake protection, 2nd edn. New York: John Wiley \& Sons.

Crowley, H., M. Colombi, V. Silva, N. Ahmad, M. Fardis, G. Tsionis, A. Papailia, F. Taucer, et al. 2011. D3.1 Fragility functions for common RC building types in Europe. SYNER-G Deliverable 3.1. http://www.vce.at/SYNER-G/files/dissemination/deliver ables.html. Accessed 12 Dec 2021.

Crowley, H., S. Ozcebe, R. Spence, R. Foulser-Piggott, M. Erdik, and K. Alten. 2012. Development of a European building inventory database. In Proceedings of the 15th World Conference on Earthquake Engineering, 24-28 September 2012, Lisbon, Portugal.
Crowley, H., R. Pinho, J. Elk, and J. Uilenreef. 2019. Probabilistic damage assessment of buildings due to induced seismicity. Bulletin of Earthquake Engineering 17: 4495-4516.

Crowley, H., D. Rodrigues, V. Silva, V. Despotaki, L. Marins, X. Romão, J.M. Castro, N. Pereira, et al. 2019. The European seismic risk model 2020 (ESRM20). In Proceedings of the 2nd International Conference on Natural Hazards and Infrastructure, 23-26 June 2019, Chania, Greece.

Crowley, H., V. Silva, P. Kalakonas, L. Martins, G. Weatherill, K. Pitilakis, E. Riga, B. Borzi, and M. Faravelli. 2020a. Verification of the European seismic risk model (ESRM20). In Proceedings of the 17th World Conference on Earthquake Engineering, 13-18 September 2020a, Sendai, Japan.

Crowley, H., V. Despotaki, D. Rodrigues, V. Silva, D. Toma-Danila, E. Riga, A. Karatzetzou, Z. Zugic, et al. 2020b. Exposure model for European seismic risk assessment. Earthquake Spectra 36(1). https://doi.org/10.1177/8755293020919429.

Crowley, H., V. Despotaki, D. Rodrigues, V. Silva, C. Costa, D. Toma-Danila, E. Riga, A. Karatzetzou, et al. 2020c. European exposure model data repository (v0.9). Zenodo. https://doi.org/ 10.5281/zenodo.4402820. Accessed 12 Dec 2021.

Crowley, H., V. Despotaki, V. Silva, D. Dabbeek, X. Romão, N. Pereira, J.M. Castro, and J. Daniell et al. 2021. Model of seismic design lateral force levels for the existing reinforced concrete European building stock. Bulletin of Earthquake Engineering 19: 2839-2865.

Crowley, H., V. Silva, L. Martins, X. Romão, and N. Pereira. 2021. Open models and software for assessing the vulnerability of the European building stock. In Proceedings of the 8th International Conference on Computational Methods in Structural Dynamics and Earthquake Engineering, 28-30 June 2021, Streamed from Athens, Greece.

Dabbeek, J., and V. Silva. 2019. Modelling the residential building stock in the Middle East for multi-hazard risk assessment. Natural Hazards 100: 781-810.

Dabbeek, J., V.Silva, C. Galasso, and A. Smith. 2020. Probabilistic earthquake and flood risk assessment in the Middle East. International Journal of Disaster Risk Reduction 49: Article 101662.

EERI (Earthquake Engineering Research Institute). 2000. World housing encyclopedia. Oakland, CA: EERI. https://www.worldhousing.net/. Accessed 12 Dec 2021.

Erdik, M., K. Sesetyan, M. Demircioglu, C. Tüzün, D. Giardini, B. Mansouri, S. Lodi and H. Al-nimry, et al. 2012. Assessment of Seismic Hazard in the Middle East and Caucasus: EMME (Earthquake Model of Middle East) Project. In Proceedings of the 15th World Conference on Earthquake Engineering, 24-28 September 2012, Lisbon, Portugal.

FEMA (Federal Emergency Management Agency). 1988. Rapid visual screening of buildings for potential seismic hazards: A handbook. FEMA 154. Washington, DC: FEMA.

FEMA (Federal Emergency Management Agency). 2003. HAZUSMH MR4 technical manual. Washington, DC: FEMA.

Gallagher, H., B. Farmer, C. Mendoza, C. Lee, H. Dickson, and M. Greene. 2013. GEM building taxonomy testing and evaluation, GEM building taxonomy global component. Oakland, CA: Earthquake Engineering Research Institute.

Grigoratos, I., J. Dabbeek, M. Faravelli, A. Di Meo, V. Cerchiello, B. Borzi, R. Monteiro, and P. Ceresa. 2016. Development of a fragility and exposure model for Palestine-Application to the city of Nablus. ProcediaEng 161: 2023-2029.

Grünthal, G. 1998. European macroseismic scale 1998 (EMS-98). Cahiers du Centre Européen de Géodynamique et de Séismologie 15, Centre Européen de Géodynamique et de Séismologie, Luxembourg. 
Jaiswal, K.S., and D.J. Wald. 2008. Creating a global building inventory for earthquake loss assessment and risk management. U.S. Geological Survey Open-File Report 2008-1160. Washington, DC: U.S. Department of the Interior, U.S. Geological Survey.

Kalman-Šipoš, T., and M. Hadzima-Nyarko. 2017. Rapid seismic risk assessment. International Journal of Disaster Risk Reduction 24: 348-360.

Lee, W.V., A. Pomonis, E. So, and R. Spence. 2011. Existing building stock classification in the Cambridge Earthquake Impact Database (CEQID). Report submitted in the context of the "Global Earthquake Consequences Database" global component. Pavia, Italy: GEM Foundation.

Martins, L., and V. Silva. 2021. Development of a fragility and vulnerability model for global seismic risk assessment. Bulletin of Earthquake Engineering 19: 6719-6745.

Motamed, H., A. Calderon, V. Silva, and C. Costa. 2019. Development of a probabilistic earthquake loss model for Iran. Bulletin of Earthquake Engineering 17: 1795-1823.

Mouroux, P., E. Bertrand, M. Bour, B. Le Brun, S. Depinois, and P. Masure. 2004. The European RISK-UE project: An advanced approach to earthquake risk scenarios. In Proceedings of the 13th World Conference on Earthquake Engineering, 1-6 August 2004, Vancouver, Canada, paper no. 3329.

Nassirpour, A., C. Galasso, and F. D'Ayala. 2018. A mobile application for multi-hazard physical vulnerability prioritization of schools. In Proceedings of the 16th European Conference on Earthquake Engineering, 18-21 June 2018, Thessaloniki, Greece.

OmniClass. 2006. OmniClass: A strategy for classifying the built environment. Introduction and user's guide, 1 st edn. Released on 28 March 2006. Alexandria, VA: Omniclass Secretariat, Construction Specifications Institute. https://www.csiresources.org/ standards/omniclass. Accessed 1 Feb 2022.

Pittore, M., M. Wieland, and K. Fleming. 2017. Perspectives on global dynamic exposure modelling for geo-risk assessment. Natural Hazards 86(S1): S7-S30.

Romão, X., J.M. Castro, N. Pereira, H. Crowley, V. Silva, L. Martins, and D. Rodrigues. 2019. European physical vulnerability model.
SERA Deliverable D26.5. https://eu-risk.eucentre.it/wp-content/ uploads/2019/08/SERA_D26.5_Physical_Vulnerability.pdf. Accessed 12 Dec 2021.

Romão, X., N. Pereira, J.M. Castro, F. De Maio, H. Crowley, V. Silva, and L. Martins. 2020. European building vulnerability data repository (v1.2). Zenodo. https://doi.org/10.5281/zenodo. 4719240. Accessed 12 Dec 2021.

Rossetto, T., I. Ioannou, and D.N. Grant. 2014. Guidelines for empirical vulnerability assessment. GEM Technical Report 2014-11. Pavia, Italy: GEM Foundation.

Silva, V., D. Amo-Oduro, A. Calderon, C. Costa, J. Dabbeek, V. Despotaki, L. Martins, M. Pagani, et al. 2020. Development of a global seismic risk model. Earthquake Spectra 36(1). doi.org/ https://doi.org/10.1177/8755293019899953.

Silva, V., H. Crowley, and M. Colombi. 2014. Fragility function manager tool. In SYNER-G: Typology definition and fragility functions for physical elements at seismic risk, ed. K. Pitilakis, H. Crowley, and A. Kaynia, 385-402. Dordrecht: Springer.

Silva, V., C. Yepes-Estrada, J. Dabbeek, L. Martins, and S. Brzev. 2018. GED4ALL - Global exposure database for multi-hazard risk analysis - Multi-hazard exposure taxonomy. GEM Technical Report 2018-01. Pavia, Italy: GEM Foundation.

Vellinga, M., P. Oliver, and A. Bridge. 2007. Atlas of vernacular architecture of the world. London: Routledge.

Villar-Vega, M., and V. Silva. 2017. Assessment of earthquake damage considering the characteristics of past events in South America. Earthquake Engineering and Soil Dynamics 99: 86-96.

Wieland, M., M. Pittore, S. Parolai, and J. Zschau. 2012. Remote sensing and omnidirectional imaging for efficient building inventory data capturing: Application within the earthquake model Central Asia. In Proceedings of the IEEE IGARSS 2012, 22-27 July 2012, Munich, Germany, 3010-3013.

Yepes-Estrada, C., V. Silva, J. Valcárcel, A. Acevedo, N. Tarque, M. Hube, G. Coronel, and H. Santamaría. 2017. Modelling the residential building inventory in South America for seismic risk assessment. Earthquake Spectra 33(2): 581-604. 